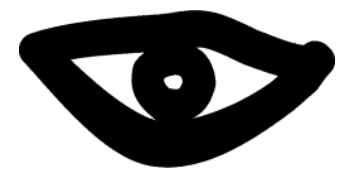

\title{
Formação continuada dos orientadores do PNAIC: contributos e desafios para as escolas públicas
}

\author{
Maria Auxiliadora Silva Cavalcante, Adriana Cavalcanti dos Santos, \\ Marinaide Lima de Queiroz Freitas, Abdizia Maria Alves Barros \\ Universidade Federal de Alagoas
}

\begin{abstract}
Resumo
Visando elucidar em que medida o processo de formação continuada em rede de docentes orientadores do Pacto Nacional de Alfabetização na Idade Certa (PNAIC) apresentou contributos e, ou, enfrentou desafios nas escolas públicas em Alagoas/Brasil, analisamos uma amostragem de questionários avaliativos aplicados com os orientadores de estudos em contexto de avaliação do processo de formação. Foram realizadas entrevistas semiestruturadas com orientadores de estudos. Desses, selecionamos para compor a amostra $10 \%$, perfazendo um total 30 questionários. As reflexões apontam que a formação docente em nível nacional, em Alagoas, implicou em contributos, sobretudo, no aprofundamento teórico-metodológico sobre as áreas do conhecimento Língua Portuguesa e Matemática.
\end{abstract}

Palavras-Chave: Formação continuada, desafios, PNAIC

\section{Motivação da Pesquisa}

Visando compreender em que medida o processo de formação continuada em rede de docentes orientadores de estudo que fazem parte do Pacto Nacional de Alfabetização na Idade Certa (PNAIC), realizado no ano de 2014, apresentou contributos e/ou, enfrentou desafios nas escolas públicas em Alagoas/Brasil, analisamos uma amostragem de 30 (trinta) questionários no universo de 300 (trezentos), aplicados com os orientadores de estudos em contexto de avaliação do processo de formação.

Os referidos orientadores de estudos do PNAIC, sujeitos dessa investigação, eram sujeitos responsáveis pelo processo de formação dos professores alfabetizadores, que atuavam do $1^{\circ}$ ao $3^{\circ}$ ano do ensino fundamental, nas redes públicas municipais e estaduais que assumiram essa função a partir da demanda dos municípios e do estado. O orientador deveria conciliar com suas atividades da atuação profissional a exigências de dedicação a participação no referido PNAIC. Tendo assim, disponibilidade para se ausentar de suas redes para participar do processo de formação no âmbito das universidades, no nosso caso a Universidade Federal de Alagoas (UFAL). E, posteriormente, formar os professores do ciclo de alfabetização a partir do trabalho com os direitos de aprendizagem de Língua Portuguesa e Matemática sugeridos pelo PNAIC.

Nesse sentido, no Brasil, por meio de parcerias, as universidades e o Ministério da Educação (MEC) vem desenvolvendo programas de formação continuada de professores em rede ao longo do século XXI, Programa de Alfabetização de Professores Alfabetizadores (PROFA), em 2001. Posteriormente, implementou-se o Próletramento, como mobilização pela Qualidade da Educação, em 2005. Nesse contexto, o PNAIC que vem se desenhando como mais uma política de continuidade do governo brasileiro direcionado à formação continuada de alfabetizadores.

O PNAIC surge como um compromisso formal assumido pelos Governo Federal, do Distrito Federal, dos Estados e Municípios no Brasil com o objetivo de assegurar que todas as crianças estejam alfabetizadas até os oito anos de idade, ao final do $3^{\circ}$ ano do ensino fundamental. O PNAIC se propõe a garantir o processo de formação do alfabetizador, o processo de avaliação e acompanhamento dos resultados dos alunos e a disponibilização de materiais didáticos nas escolas para o uso do educador e do aluno.

\footnotetext{
Maria Auxiliadora da Silva Cavalcante, Professora Associado III do Programa de Pós-Graduação em Educação da Universidade Federal de Alagoas, Brasil. Graduada em Letras, Doutorado em Linguística e Pós-Doutoorado em Educação.

Correspondencia: maria_auxiliadora8@hotmail.com

Selección y peer-review bajo responsabilidad del Grupo de Investigación G000422-GIPDAE, Universidade da Coruña, España.
} 
Dado o exposto, conhecer os contributos do processo de formação continuada do orientador de estudo e, consequentemente, do professor alfabetizador. Bem como os desafios (im)postos por uma política de formação continuada em rede, configurou-se como um dado importante para se pensar também as contribuições e o lugar das universidades no processo de formação docente.

\section{O PNAIC em Alagoas}

Em Alagoas, o processo de formação em rede do PNAIC foi assumido em 2014 pela Universidade Federal de Alagoas (UFAL), mais especificamente pelo Centro de Educação (CEDU), por meio do Núcleo de Pesquisa e Alfabetização em Alagoas (NEPEAL), o que anteriormente era assumido pela Universidade de Pernambuco (UFPE). Nesse contexto, deparamo-nos com o desafio de orientar e iniciar o processo de formação do grupo de formadores de linguagem em diálogo com os formadores de Matemática de modo que entendêssemos e ao mesmo tempo possibilitássemos a articulação entre as áreas nos momentos de formação dos orientadores de estudos. Esses grupos por sua vez "formariam" os orientadores de estudos para em suas redes formarem os professores alfabetizadores.

Participaram do processo de formação em rede do PNAIC em Alagoas 7.328 professores alfabetizadores, 300 orientadores de estudo, 20 formadores, 07 supervisores da IES e a coordenação geral do programa. Além desses, também foi importante a participação dos coordenadores locais do PNAIC, os quais tinham a função de fazer a articulação entre a universidade e as redes, bem como acompanhar o desenvolvimento da formação em cada município.

O caderno de apresentação do PNAIC da Alfabetização matemática (2014) explicita: "a alfabetização Matemática na perspectiva de letramento foi um pressuposto adotado em consonância com o material de formação em linguagem. Dessa forma, a Alfabetização Matemática é entendida como um instrumento para a leitura do mundo [...]”. Demandando assim um "novo" modelo de formação de professores, como também, uma "nova" forma de ensino. Isso vem aguçando o olhar das supervisoras do PNAIC, da universidade, sobre as possibilidades e os limites da articulação entre as referidas linguagens, na formação de professores, justificando-se pela relevância da construção de uma cultura de interação entre essas áreas rompendo com a cultura da disciplinaridade, do isolamento entre as áreas do currículo, como também com as ideias construídas sobre a supremacia de uma área sobre a outra.

Nessa direção sentimos a necessidade de partirmos para a pesquisa de abordagem quantiqualitativa, tendo como objeto de estudo a compreensão de como os orientadores de estudo, enquanto multiplicadores, um trabalho articulado.

Vale salientar que a ampliação das perspectivas de ensino da linguagem e ensino da matemática, ambas em contextos de letramentos, articuladas impõe desafios à formação continuada do professor, sobretudo, daqueles que não tiveram ao longo de seus processos de formação inicial e/ ou continuada a possibilidade de refletir sobre os pressupostos do letramento. Nesse contexto, o letramento é entendido como estado ou condição em que vivem e interagem indivíduos ou grupos sociais letrados (Soares, 1998).

\section{Dos contributos do processo de formação do PNAIC}

$\mathrm{Na}$ prática, um processo de formação continuada em rede permite-nos deparar com profissionais que têm diferentes formações iniciais e significativas experiências profissionais que lhes permitem um frutífero diálogo entre o mundo da vida profissional e os desafios das novas políticas de formação contínua. Assim, a perspectiva de formação continuada docente deve estar relacionada ao da "aprendizagem permanente que considera os saberes e as competências docentes como resultados não só de formação profissional e do exercício da docência, mas também de aprendizagens realizadas ao longo da vida, 
dentro e fora da escola" (Mizukami et al, 2003, p. 31).

No contexto de formação continuada do PNAIC, ao questionarmos quais as contribuições do processo de formação enquanto formadores de professores, a orientadora de estudo Edúlina (nome fictício) respondeu:

Para a minha atuação como educador contribuiu bastante, principalmente, em priorizar os direitos de aprendizagens de cada ano, intercalando os conteúdos de língua portuguesa com os de matemática. Os estudos são desenvolvidos em grupos na formação. A metodologia [utilizada na formação do PACTO] foi bastante lúdica, associada aos conteúdos de matemática com a construção de alguns jogos. Os direcionamentos de algumas atividades foram maravilhosas. $\mathrm{Na}$ formação de língua portuguesa, a orientação sobre os eixos da análise linguística ficaram claras e criativas para entendê-las (Orientadora Edúlina, 39 anos, 24 anos de docência).

Constata-se na fala de Edúlina que os direitos de aprendizagem propostos pelo PNAIC foram de fato assimilados pela orientadora. Esses direitos, em relação ao Componente Currilar Língua Portuguesa orientam que:

A Educação Básica empreende seu trabalho político-pedagógico em busca de garantir o direito à alfabetização de crianças dos seis aos oito anos de idade, pois a linguagem constitui o sujeito na interação social. Para isto, é necessário proporcionar-lhes vivências e experiências de oralidade, leitura e escrita que envolvam seu mundo físico, social, cultural, a partir das quais possam compreender e produzir textos orais e escritos variados e de qualidade, de diferentes gêneros textuais, com diversas finalidades, com vistas à sua participação autônoma em variadas esferas de interação social (PNAIC, 2012, p.36)

No texto de referência do PNAIC, em relação aos direitos de aprendizagem da Língua Portuguesa, estão descritos esses direitos:

I. Falar, ouvir, ler e escrever textos, em diversas situações de uso da língua portuguesa, que atendam a diferentes finalidades, que tratem de variados temas e que sejam compostos por formas relacionadas aos propósitos em questão;

II. Falar, ouvir, ler e escrever textos que propiciem a reflexão sobre valores e comportamentos sociais, participando de situações de combate aos preconceitos e atitudes discriminatórias: preconceito de raça, de gênero, preconceito a grupos sexuais, a povos indígenas, preconceito linguístico, dentre outros;

III. Apreciar e compreender textos falados e escritos do universo literário, como contos, fábulas, poemas, dentre outros;

IV. Apreciar e usar, em diversas situações, os gêneros literários do patrimônio cultural da infância, como parlendas, cantigas, trava línguas, dentre outros;

V. Falar, ouvir, ler e escrever textos relativos à divulgação do saber escolar/ científico, como verbetes de enciclopédia, verbetes de dicionário, resumos, dentre outros, e textos destinados à organização do cotidiano escolar e não escolar, como agendas, cronogramas, calendários, dentre outros;

VI. Participar de situações de fala, escuta, leitura e escrita de textos destinados à reflexão e discussão acerca de temas sociais importantes, por meio de reportagens, artigos de opinião, cartas de leitores, dentre outros (PNAIC, 2012, p.36-39).

Esses direitos foram organizados em eixos estruturantes e objetivos de aprendizagem que deveriam ser alcançados ao longo ciclo do processo de alfabetização do $1^{\circ}$ ao $3^{\circ}$ ano do ensino fundamental, cujo trabalho pedagógico deveria tomar como premissa básica o trabalho interdisciplinar, numa perspectiva do letramento, levando em conta os quatro princípios centrais ao longo do desenvolvimento do trabalho pedagógico: em primeiro lugar, exige-se um ensino sistemático e problematizador; já que a escrita alfabética é complexa; em segundo lugar procura-se desenvolver a capacidade de leitura e de produção de textos que ocorre durante todo o processo de escolarização, e deve ser iniciado logo no início da Educação Básica, garantindo acesso precoce a gêneros discursivos de circulação social e a situações de interação em que as crianças se reconheçam como protagonistas de suas próprias histórias; o terceiro princípio foca no conhecimento das diferentes áreas apropriadas pelas crianças, de modo que elas possam ouvir, falar, ler, escrever sobre temas diversos e agir na sociedade; e o quarto principio dá importância a ludicidade ao 
cuidado com as crianças são condições básicas nos processos de ensino e de aprendizagem.

De modo geral, o processo de formação do PNAIC, como ressaltou a orientadora de estudos Edúlina, atingiu ao seu propósito, ao possibilitar aos orientadores de estudo um diálogo teóricoprático sobre os eixos de aprendizagem do referido programa. Com relação à metodologia adotada, o "lúdico" se caracterizou como uma das possibilidades de diálogo. No entanto, o material do PNAIC sugere um diálogo teóricoprático até certo ponto denso, considerando o formato da formação. Por isso, é preciso considerar o professor, enquanto autor, e a escola, enquanto cenário (Torres, 1999). Para que possam se implementar uma cultura de formação no interior da escola.

Segundo Torres (1999, p. 106) "recuperar a prática como espaço privilegiado de formação e reflexão significa considerar a prática pedagógica como espaço mais importante, permanente e ativo de formação docente". Nessa perspectiva, a continuidade do processo de formação do PNAIC é evidenciada no depoimento, ficando explícito que:

Os conteúdos abordados nos encontros retornam aos estudos dos cadernos anteriores aprimorando os conhecimentos dos eixos e, principalmente, dos direitos de aprendizagem de matemática e de língua portuguesa. A metodologias de sala de aula diversificada através de leitura deleite, textos humorísticos, géneros textuais diversos, leitura compartilhada, slides bem elaborados, as oficinas de leitura, confecção de jogos (que ajudam na alfabetização), estudos dirigidos, trabalhos em grupos, elaboração de sequências didáticas, análise de textos de alunos, além de um leque de oportunidades para que seja transmitidos aos seus professores alfabetizadores condições de garantia de planejamento coerente aos que precisam para alfabetizar e letrar (Orientadora Cira, 53 anos, 27 anos de docência).

Nesse fragmento fica explícito que em se tratando de um processo de formação continuada garantir a continuidade das discussões teórico-práticas pode possibilitar um maior aprofundamento dos saberes abordados. Observamos o reconhecimento da utilização de metodologias sugeridas pelo material do
PNAIC, que por sua natureza propõem reflexões, vivências e planejamento no/do fazer pedagógico. A participação ativa, crenças, metas, objetivos, expectativas, conhecimentos dos professores e experiências se interrelacionam (Mizukami, 2003).

\section{Dos desafios do processo de formação do PNAIC em Alagoas}

No processo de formação continuada os professores são convidados a socializarem suas práticas, analisarem, estudarem e planejarem o seu fazer pedagógico. Eles se colocam como co-autores do processo de formação continuada. Esse deslocamento de lugares, de receptores para sujeitos autores, implica também em desafios ao processo de formação docente. Nesse contexto, aos fomentarmos a reflexão sobre os desafios enfrentados pelos orientadores de estudos junto aos professores alfabetizadores, observamos que:

O maior desafio é a credibilidade [do professor] implantada durante o período das atividades. $\mathrm{O}$ compromisso com as atividades por parte dos professores alfabetizadores. Assumir uma postura ética, não medir a capacidade de ninguém, mas respeitá-la dentro do papel que encaramos e $\mathrm{o}$ prazer em ajudá-lo nas dificuldades apresentadas [durante o processo de formação]. Enfim é um somatório favorável, chegamos a conclusão de que a comunicação e o querer aprender possibilitam o nosso trabalho envolvendo interesse de ambas as partes (Orientadora Clea, 51 anos, 25 anos de docência)

De fato, não é neutro o processo de açãoreflexão-ação na/sobre a prática a partir de diferentes referenciais teórico-práticos. Pois, estamos diante de um grupo profissional que vem construindo ao longo do tempo saberes docentes sobre o que, como e para que ensinar. Segundo Tardif (2002, p.15) "o saber é social por ser adquirido no contexto de uma socialização profissional, onde é incorporado, modificado, adaptado em função dos momentos e das fases de uma carreira".

Um processo de formação continuada em que se alimentam do saber-fazer-docente implica em um processo de diálogo entre 
formadores e formandos. Nesse contexto, vão surgindo inúmeras dificuldades como podemos observar no depoimento a seguir:

A realização das atividades práticas com os alunos; o acesso ao sistema por alguns professores (não conseguem acessar); a falta de momento de planejamento coletivo nas escolas; pouco interesse da coordenação; e, [participação da] gestão por não ter conhecimento do conteúdo do curso do Pacto, são algumas das dificuldades (Orientadora Marta, 36 anos, 15 anos de docência).

Este extrato deixa explícito que um processo de formação continuada requer dos seus agentes diretos e indiretos um envolvimento de modo a viabilizar o processo. Para isso, precisamos permitir que todos tenham acesso aos saberes teórico-práticos discutidos durante a formação.

O depoimento nos chama a atenção também para com a cultura de resistência do professor para com novas vivencias de estratégias e conteúdos de ensino, pois, é sabido que "o cotidiano da ação docente é evidentemente situado e moldado em contextos que afetam seus atores e que condicionam a racionalidade de suas práticas" (Terrien e Souza, 2000 p. 115).

$O$ acesso a informatização também se apresentou como um desafio, a medida que nem todos os professores têm acesso aos sistema do PNAIC e/ou sabiam alimentá-lo.

Numa perspectiva geral, observa-se que a grande maioria dos orientadores de estudos considerou a formação vivenciada no PNAIC como muito proveitosa. A orientadora Ana apresenta uma síntese das principais contribuições do PNAIC, na formação dos professores orientadores e alfabetizadores.

Os encontros foram sempre muito satisfatórios, mesmo acontecendo aos sábados e com os professores muito cansados. Eles são bem participativos e gostam muito de partilhar as experiências de sala de aula. Colocam-se e discutem os conteúdos, relembram que os conhecimentos não são novidades, mas trazem um novo jeito de trabalhar a alfabetização, o letramento e principalmente a matemática. Depois dos encontros, pude observar uma mudança significativa nas práticas da maioria dos professores alfabetizadores que fazem parte do PNAIC (Orientadora Ana, 39 anos, 14 anos de docência).

A reflexão da orientadora aponta que o modelo de formação em rede do PNAIC possibilitou o movimentum de um processo de reflexão sobre a prática docente por meio da "partilha de experiências", além de aprendizagens de estratégias para alfabetizar e letrar as crianças no ciclo de alfabetização, como também percebeu mudanças na prática da maioria das alfabetizadoras.

A orientadora Júlia, com 33 anos de idade e 14 anos de docência na Educação Básica ressalta o que deu certo e também o que ainda é preciso melhorar. Na sua visão, as atividades relacionadas aos direitos de aprendizagem, as experiências trocadas nas formações, a prática dos jogos, por meio de oficinas, bem como as leituras e discussões e as atividades de casa, que deveriam ser feitas na sala de aula antes do próximo encontro. Demonstrando assim que a proposta de formação do PNAIC atingiu seus objetivos a medida que as estratégias formativas proporcionaram aprendizagens.

Com relação ao que ainda é preciso melhorar na formação ofertada pelo PNAIC, Júlia, como todas as trinta orientadoras de estudo, cujas entrevistas serviram de base para este artigo, refere que "o tempo é curto para estudar os cadernos, pois ver o caderno de grandezas e medidas e educação e estatísticas em 24 é pouco". O tempo pedagógico destinado ao processo de formação, de fato, era insuficiente para demanda de saberes que deveriam ser trabalhados com profundidade nos encontros de formação, considerando que para muitos orientadores de estudo e professores alfabetizados eram desconhecidos

Além da questão do tempo, a maioria dos professores alfabetizadores reivindica que nos meses em que exista três sábados dentro do mesmo mês seja suprimido um, pois o terceiro encontro torna-se muito cansativo, motivo alegado por muitos professores para fazerem as leituras em casa.

Ao questionarmos ainda os orientadores de estudos se houve relatos quanto a melhoria e inovação em suas atividades em sala de aula, o grupo evidenciou que "muito bom, pois tirei as 
dúvidas. E [essa formação] vai contribuir para o desenvolvimento dos trabalhos na formação com os professores alfabetizadores". Evidenciaram assim o propósito de um processo de formação que deveria culminar em diálogos reflexivos na escola. Bem como afirmou a orientadora "Foi muito proveitoso, pois aprendemos novos métodos de como se trabalhar matemática com os alunos". Nesse contexto, o diálogo sobre o ensino da matemática na perspectiva do letramento, proposta pelo referido Pacto, pode ser considerado durante o processo de formação continuada. Anunciar o olhar dos orientadores de estudos faz-nos reconhecer que "a consciência coletiva nasce da confluência entre a organização como instancia de ação e reflexão e a participação como instancia de ação e reflexão e a participação como engajamento e abertura (Lima, 2007, p. 173) para se repensar o processo de formação e a vivencia de novas práticas de alfabetização e letramento.

No entanto, para alguns o processo de formação continuada "Me senti numa pósgraduação. Acrescentei a minha prática conhecimentos de fundamental importância para o meu cotidiano em sala de aula". De diferentes formas, o processo de formação continuada vai implicar na construção de saberes e a avaliação da complexidade do processo depende do olhar do sujeito em formação, que muitas vezes não "são pensadas a partir das necessidades das escolas e dos sujeitos em formação, imersa numa história local (Ezpeleta e Rockwell, 1989)

Os orientadores revelaram ainda que a formação continuada proporciona possibilidades para mudanças e é isso que fará fazer a diferença, porque um processo de formação implica também alterações sobre o saber-fazer-docente e da própria concepção do seu papel e função na escola (Dias-da-Silva, 1994, p.45).

Por fim, a formação garantiu o repensar das práticas e as possibilidades do processo de formação. Os momentos de formação foram muito ricos pois os formadores adequaram os materiais a realidade de cada orientador, mostrando que é possível realizarmos os encontros e transformarmos os materiais existentes na natureza.

\section{Considerações Finais}

Este trabalho teve por objetivo principal tentar compreender em que medida o processo de formação continuada em rede de docentes orientadores de estudo que fazem parte do Pacto Nacional de Alfabetização na Idade Certa (PNAIC), realizado no ano de 2014, apresentou contributos e/ou, enfrentou desafios nas escolas públicas em Alagoas/Brasil. Para isso, analisamos uma amostragem de de 30 (trinta) questionários no universo de 300 (trezentos), aplicados com os orientadores de estudos em contexto de avaliação do processo de formação.

Os referidos orientadores de estudos do PNAIC, sujeitos dessa investigação, eram sujeitos responsáveis pelo processo de formação dos professores alfabetizadores, que atuavam do $1^{\circ}$ ao $3^{\circ}$ ano do ensino fundamental, nas redes públicas municipais e estaduais que assumiram essa função a partir da demanda dos municípios e do estado.

Consideramos que o PNAIC, hoje contribui de forma significativa para a formação continuada dos professores no Brasil, oportunizando também a formação de multiplicadores para que tenhamos em cada município, sujeitos capazes de contribuir com o processo de reflexão da prática cotidiana em sala de aula. Esta oportunidade de rever, as concepções teórico-metodológicas da Linguagem e da Matemática, trouxe novas possibilidades para o professor que vinha sem condições de avançar na sua prática docente, considerando que os processos de formação inicial e continuada dos professores no Brasil, sobretudo com relação à formação destinada ao processo de alfabetização, ainda, deixa muito a desejar no que diz respeito a construção de competências para ensinar as diferentes áreas do conhecimento.

O PNAIC ao contar com a parceria das IES na disseminação do processo de formação continuada para garantir condições para a 
implementação do referido programa, consideramos que não podemos continuar sem as devidas condições de infraestrutura para continuar a ser coordenado pelas IES. Precisamos das mínimas condições, nos faltam espaços para organizar a formação, como também para organizar a coordenação em todo o seu aspecto geral.

Sentimos falta, enquanto Universidade coordenadora do programa receber os cadernos da formação, só funcionamos graças aos serviços de xérox e de parceria com os municípios, até o presente momento, não temos os materiais (cadernos) de formação, de Língua Portuguesa e Matemática, ou seja, não recebemos os Kits, para formação. Solicitamos com urgência todos os cadernos já publicados 2013 - língua portuguesa; 2014 - matemática e os de 2015, condição para iniciarmos 2015, chegar cadernos na Universidade Federal de Alagoas.

\section{Referências}

Brasil (2013). Pacto Nacional pela Alfabetização na Idade Certa- PNAIC. Disponivel In: http://pacto.mec.gov.br/images/pdf/orientador_ de_estudo.pdf

Brasī (2012). Formação de Professores. Disponivel In: http://pacto.mec.gov.br/images/ pdf/Formacao/Formacao_de_professores_MIO LO.pdf

Brasil (2012). Ministério da Educação. Secretaria da Educação Básica. Elementos conceituais e metodológicos para definição dos diretos de aprendizagem e desenvolvimento do ciclo de alfabetização $\left(1^{\circ}, 2^{\circ}\right.$, e $3^{\circ}$ anos $)$ do ensino fundamental. Brasília.

Dias-da-Silva, M. H. G. F (1984). Saberes docente: repensando a prática pedagógica. In Cadernos de Pesquisa. São Paulo, no 89.

Ezpeleta, J. Rockwell, E (1989) Pesquisa participante. São Paulo, Cortez e Autores Associados.

Lima, M. E. C. C (2007). Trabalho colaborativo formação docente. In VARANI, A. et al. Narrativas docentes: trajetórias de trabalhos pedagógicos. Campinas, SP: Mercado de Letras.

Mizukami, M. G. N. et al (2002). Escola e aprendizagem da docência: processos de investigação e formação. São Carlos: EduFSCar.

Tardif, Maurice (2002). Saberes docente $e$ formação profissional. 3 ed. Petrópolis, RJ: Vozes.

Torres, R. M (1999). Nuevo rol docente: qué modelo de formación, para qué modelo educativo? In Fundación Santillana. Aprender para el futuro. Nuevo marco de la tarea docente. Documentos en Debate. Madrid.

Therrien, Jacques. Souza, Angela (2000). Cultura docente e gestão pedagógica: a racionalidade prática dos saberes do saber-fazer. In. Therrien, Jacques. \& Damasceno, Maria Nobre (Orgs). Artesões de outro oficio: Múltiplos Saberes e Práticas no Cotidiano Escolar. São Paulo: Annablume; Fortaleza: Secretaria de Cultura e Desporto do Governo do Estado do Ceará. 